Tạp chí Khoa học và Công nghệ biển T12 (2012). Số 2. Tr 11 - 18

\title{
KẾT QUẢ NGHIÊN CỬU VỀ HÀM LƯợNG VÀ KHẢ NĂNG XỬ LÍ KIM LOẠI NẬNG NƯớC THẢI CÔNG NGHIỆP CHẾ BIẾN THỦY SẢN TRÊN AEROTANK
}

\author{
NGUYẼ̃N PHƯớC HÒA
}

Trường Đại học Nha trang

\begin{abstract}
Tóm tắt: Bài báo trình bày kết quả nghiên cứu về sụ biến động hàm luợng và hiệu quả xử lí sinh họ 7 kim loại nặng $\left(\mathrm{Pb} ; \mathrm{Hg} ; \mathrm{As} ; \mathrm{Cd} ; \mathrm{Cr}^{+3} ; \mathrm{Cu} ; \mathrm{Zn}\right)$ có trong nước thải công nghiệp chế biến thủy sản trên Aerotank ở khoảng tải trọng tối uu tù 2.52- 5.87 (KgCOD/ $m^{3}$.ngày.đêm) và thời gian luu thuỷ lục tối uu là 18 giò̀.
\end{abstract}

\section{I. ĐẠT VẤN Đî̀}

Vấn đề vệ sinh, an toàn thực phẩm nói chung và vệ sinh, an toàn thực phẩm thủy sản nói riêng đang là mối quan tâm to lớn, thường trực đối với các nhà sản xuất thực phẩm và người tiêu dùng trong, ngoài nước vì lợi ích bảo vệ sức khỏe và nâng cao tuổi thọ cho cộng đồng trong tương lai.

Các thành phần gây không an toàn và vệ sinh cho người sử dụng thực phẩm rất đa dạng, trong đó thành phần các kim loại nặng (điện tích hạt nhân nguyên tử lớn) hiện nay đã được cộng đồng sử dụng thực phẩm chú ý.

Nhiều nghiên cứu cho thấy, các kim loại nặng là một trong những nguồn gây ô nhiễm cho môi trường, có khả năng tích lũy và rất khó phân hủy, có khả năng gây độc cho hầu hết các sinh vật trên cạn, dưới nước, trong đó có cả con người bởi sự nhiễm bẩn và hấp thụ. Theo con đường tích lũy thực phẩm qua chuỗi thức ăn, các kim loại nặng tồn tại trong môi trường khí, rắn và lỏng có thể tích lũy ở các mô cơ, xương, tim, bộ phận sinh dục, cơ quan tiêu hóa của các động, thực vật thủy sản và vận chuyển qua cho người. Đặc biệt là $\mathrm{As}, \mathrm{Cd}, \mathrm{Pb}$ không có chức năng sinh học trong cơ thể người và chúng rất độc ngay cả ở lượng vết [2].

Có nhiều loài vi sinh vật (VSV), thực vật thuỷ sinh và nhuyễn thể 2 vỏ có khả năng hấp thụ kim loại nặng. Các Thiobacillus như Thiobacillus ferrooxidans; Thiobacillus thiooxidans; Thiobacillus acidophilus; Thiobacillus organoporus là những chủng vi khuẩn có khả năng tách kim loại nặng tốt nhất [5]. Nhiều loài chim biển, nhuyễn thể 2 vỏ, rong biển, ... đã được nghiên cứu, sử dụng rộng rãi với vai trò là một chỉ thị sinh vật để đánh giá mức độ ô nhiễm biển về kim loại nặng. 
Kết quả nghiên cứu cho thấy, nước thải công nghiệp chế biến thủy sản (CBTS) có hàm lượng chất bẩn hữu cơ cao, là nguồn gây ô nhiễm trầm trọng cho các thủy vực tiếp nhận nguồn thải. Các chất bẩn hữu cơ được đánh giá qua các chỉ tiêu $\left(\mathrm{BOD}_{5} / \mathrm{Biochemical}\right.$ Oxigen Demand; COD/ Chemical Oxigen Demand; tổng $\mathrm{N}$; tổng $\mathrm{P}$; ...) có trong loại nước thải này dễ dàng được làm sạch bằng các VSV kị khí và hiếu khí có trong bùn hoạt tính ở dạng bông hoặc dạng hạt và nước thải sau khi đi qua thiết bị xử lí UASB (Upflow Anaerobic Sludge Blanket), kết hợp Aerotank ở L (Load) và HRT (Hydraulic Retention Time) tối ưu [3], luôn luôn đạt tiêu chuẩn xả thải ra môi trường loại $\mathrm{B}$ (TCVN 59452005) [1].

Các kim loại nặng, chúng tồn tại khắp nơi và có mặt hầu hết trong các chất thải rắn, khí, lỏng công nghiệp và đời sống sinh hoạt con người. Hàm lượng của chúng ở nhiều thủy vực, khu dân cư, ... nằm kề gần các khu công nghiệp không ngừng tăng lên và có nơi đã đến mức báo động. Các kim loại nặng có trong nước thải công nghiệp CBTS sẽ làm ô nhiễm các vùng thủy vực tiếp nhận nguồn thải.

Tuy nhiên, việc nghiên cứu về hàm lượng và khả năng xử lí kim loại nặng nước thải công nghiệp CBTS bằng VSV có trong bùn hoạt tính hiếu khí trên Aerotank ở $\mathrm{L}$ và $\mathrm{HRT}$ tối ưu, chưa thấy có tài liệu nào công bố.

Bài báo này, trình bày kết quả nghiên cứu về sự biến động hàm lượng $(\mathrm{mg} / \mathrm{l})$ và hiệu quả xử lí sinh học 7 kim loại nặng $\left(\mathrm{Pb} ; \mathrm{Hg} ; \mathrm{As} ; \mathrm{Cd} ; \mathrm{Cr}^{+3} ; \mathrm{Cu} ; \mathrm{Zn}\right)$ có trong nước thải công nghiệp CBTS trên Aerotank ở khoảng L tối ưu từ 2.52- $5.87\left(\mathrm{KgCOD} / \mathrm{m}^{3}\right.$.ngày.đêm) và HRT tối ưu là 18 giờ [3].

\section{VẬT LIÊ̂U VÀ PHƯƠNG PHÁP NGHIÊN CÚU}

\section{1. Đối tượng nghiên cứu}

- Nước thải công nghiệp CBTS hỗn hợp sau quá trình sản xuất, với các sản phẩm được chế biến chủ yếu từ cá, các loài giáp xác, một số loài nhuyễn thể dùng cho xuất khẩu và tiêu dùng nội địa.

- 7 kim loại nặng $\left(\mathrm{Pb} ; \mathrm{Hg} ; \mathrm{As} ; \mathrm{Cd} ; \mathrm{Cr}^{+3} ; \mathrm{Cu} ; \mathrm{Zn}\right)$ có trong nước thải hỗn hợp từ các mặt hàng thuỷ sản đông lạnh như tôm Sú, cá Thu, cua, ghẹ, mực và một số mặt hàng khô, đóng hộp, sản phẩm ăn liền thủy sản.

\section{Phương pháp nghiên cứu và xử lý số liệu thực nghiệm}

- Bình đựng mẫu nước thải hỗn hợp là các can nhựa bằng Polyetylen, dung tích 20 lít có nút vặn chặt, được rửa sạch bằng dung dịch rửa (hỗn hợp $\mathrm{K}_{2} \mathrm{Cr}_{2} \mathrm{O}_{7}$ và $\mathrm{H}_{2} \mathrm{SO}_{4}$ đậm 
đặc) trước khi đựng mẫu. Dùng nước thải hỗn hợp (mẫu) tráng can nhựa qua vài lần. Múc nước thải vào đầy can, vặn chặt nút và vận chuyển ngay về phòng thí nghiệm để phân tích lập tức các kim loại nặng ( $\left.\mathrm{Pb} ; \mathrm{Hg} ; \mathrm{As} ; \mathrm{Cd} ; \mathrm{Cr}^{+3} ; \mathrm{Cu} ; \mathrm{Zn}\right)$.

- Mẫu nước thải nguyên khai được lấy là mẫu trộn với tần suất 3 lần/ ngày, có dung lượng cho mỗi mẻ thí nghiệm là 50 - 100 lít.

- Mỗi lần thí nghiệm, các chỉ tiêu được xác định 3 lần/ chỉ tiêu và lấy giá trị trung bình.

- Sự biến động hàm lượng $(\mathrm{mg} / \mathrm{l})$ các kim loại nặng $\left(\mathrm{Pb} ; \mathrm{Hg} ; \mathrm{As} ; \mathrm{Cd} ; \mathrm{Cr}^{+3} ; \mathrm{Cu} ; \mathrm{Zn}\right)$ theo thời gian $0,3,6,9(\mathrm{~h})$ ở mỗi $\mathrm{L}\left(\mathrm{KgCOD} / \mathrm{m}^{3}\right.$.ng.đ) thí nghiệm được xác định bằng phương pháp quang phổ hấp thụ nguyên tử trên máy AAS (Atomic Absorption Spectrometer) Thermo Elemental- Model Solaar M6 Dualzeeman.

- Các thí nghiệm tiến hành với HRT tối ưu là 18 h [3] được tính bởi công thức: $H R T=\frac{V}{Q} \times 24 h$

- Các thí nghiệm tiến hành ở khoảng L tối ưu từ 2.52- $5.87\left(\mathrm{Kg} \mathrm{COD} / \mathrm{m}^{3}\right.$.ng.đ) [3] theo lưu lượng $\mathrm{Q}\left(\mathrm{m}^{3} / \mathrm{ng}\right.$.đ), nồng độ chất bẩn $\mathrm{C}\left(\mathrm{KgCOD} / \mathrm{m}^{3}\right)$ và thể tích thiết bị xử lý $\mathrm{V}$ $\left(\mathrm{m}^{3}\right)$ được tính bởi công thức: $L=\frac{Q \times C}{V}$

- Hiệu suất xử lí $\eta(\%)$ các kim loại nặng $\left(\mathrm{Pb} ; \mathrm{Hg} ; \mathrm{As} ; \mathrm{Cd} ; \mathrm{Cr}^{+3} ; \mathrm{Cu} ; \mathrm{Zn}\right)$ có hàm lượng $\mathrm{S}_{\text {vào }}$ và $\mathrm{S}_{\mathrm{ra}}(\mathrm{mg} / \mathrm{l})$ nhờ $\mathrm{VSV}$ có trong bùn hoạt tính được tính bởi công thức: $\eta=\frac{\text { Svào }- \text { Sra }}{\text { Svào }} \times 100 \%$

- Nguồn VSV sử dụng xử lí có trong bùn hoạt tính hiếu khí dạng bông, màu vàng nâu, dễ lắng (Alkaligenes- Achromobacter; Pseudomonas; Enterobacteriaeae; Athrobacter baccillus; Cytophaga- Flavobacterium; Pseudomonas- Vibrio aeromonas; Achrobacter; Hỗn hơp các vi khuẩn khác: Ecoli, Micrococus) [4] được lấy từ Aerotank của hệ thống xử lý nước thải công nghiệp CBTS đã qua kĩ thuật thích nghi [3].

- Nghiên cứu đã sử dụng phương pháp thống kê sinh học, quy hoạch thực nghiệm và hàm hoá số liệu thực nghiệm bằng phương pháp tổng bình phương cực tiểu với chương trình Microsoft Excel. Các thông số tối ưu được xác định bằng phương pháp đạo hàm hay phương pháp đồ thị.

\section{Mô hình nghiên cứu và vận hành}

Mô hình xử lí Aerotank hoạt động theo nguyên lý động từng mẻ được mô tả ở hình 1 
là một hình trụ vuông bằng nhựa PolyAcrylic, có thể tích hữu dụng 8.8 lít. Kích thước cả thiết bị: dài x rộng x cao $=160 \mathrm{~mm}$ x $160 \mathrm{~mm}$ x $510 \mathrm{~mm}$. Đáy thiết bị hình nón có chiều cao $170 \mathrm{~mm}$, đáy lớn có kích thước $160 \mathrm{~mm}$ x $160 \mathrm{~mm}$, đáy nhỏ có kích thước $40 \mathrm{~mm}$ x $40 \mathrm{~mm}$. Bên trong thiết bị có một ngăn sục khí và một ngăn lắng.

Sinh khối bùn hoạt tính dạng bông đã được thích nghi có MLSS (Mixed Liquor Suspended Solid) khoảng 4.500- 5.000 (mg/l) được khuấy trộn bằng không khí nhờ máy thổi khí với hàm lượng DO (Dissolved Oxigen) từ 3- $5(\mathrm{mg} / \mathrm{l})$. Các thí nghiệm được tiến hành với HRT tối ưu là $18 \mathrm{~h}$, với các mẫu nước thải có các $\mathrm{L}$ từ 3.852- $5.212(\mathrm{KgCOD} /$ $\mathrm{m}^{3}$.ng.đ) thuộc khoảng L tối ưu từ 2.52- $5.87\left(\mathrm{KgCOD} / \mathrm{m}^{3}\right.$.ng.đ) [3].

Theo dõi sự biến động hàm lượng (mg/l) các kim loại nặng $\left(\mathrm{Pb} ; \mathrm{Hg} ; \mathrm{As} ; \mathrm{Cd} ; \mathrm{Cr}^{+3}\right.$; $\mathrm{Cu} ; \mathrm{Zn}$ ) và $\mathrm{COD}$ trong nước thải trước và sau xử lý theo thời gian (h) và thí nghiệm sẽ kết thúc ở mỗi L khi hiệu suất khử COD ổn định. Tiếp tục tăng L lên cao bằng cách tăng nồng độ COD đầu vào và thí nghiệm sẽ kết thúc khi hiệu suất khử COD nhỏ hơn $50 \%$.

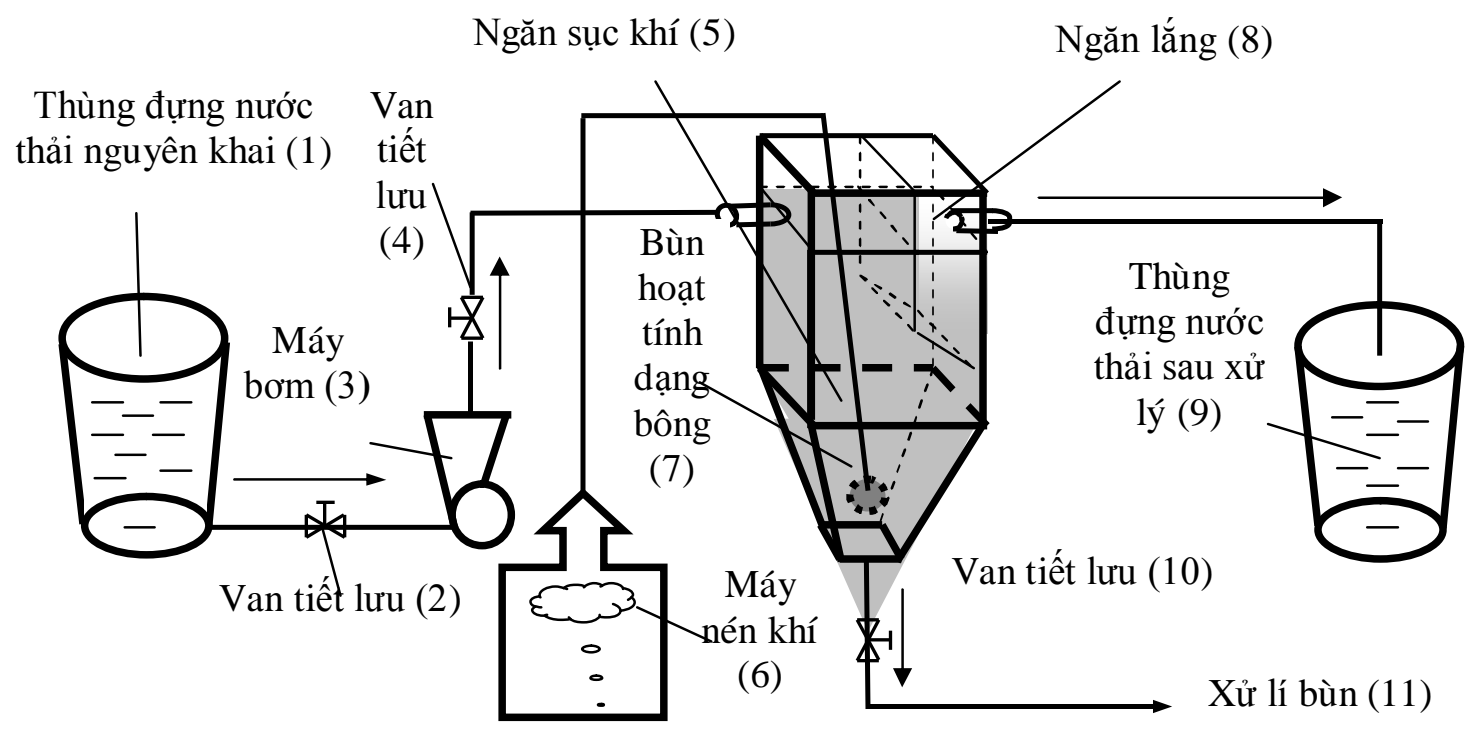

Hình 1: Mô hình Aerotank

\section{KÊTT QUẢ NGHIÊN CÚU VÀ THẢO LUẬN}

\section{Biến động hàm lượng 7 kim loại nặng trong nước thải CBTS trên Aerotank}

Các kim loại nặng được bảo tồn và hầu như khó bị phân hủy trong tự nhiên. Chúng có thể biến đổi dưới nhiều dạng khác nhau với tính năng mạnh mẽ hơn và nguy hiểm hơn 
các chất ban đầu. Theo chu trình tích tụ sinh học, các kim loại nặng như $\mathrm{Pb}, \mathrm{Hg}, \mathrm{As}, \mathrm{Cd}$, $\mathrm{Cr}, \mathrm{Cu}, \mathrm{Zn}, \mathrm{Ni}, \mathrm{Se}, \mathrm{Ag}, \mathrm{Sn}, \mathrm{Ba}$... trong nước, trong đất đã xâm nhập vào các mô động vật hoặc thực vật và theo chuỗi thức ăn, chúng được tích tụ lại trong cơ thể con người ngày càng nhiều sẽ ảnh hưởng đến sức khỏe và chất lượng sống của chúng ta.

Kết quả nghiên cứu xác định sự biến động hàm lượng $(\mathrm{mg} / \mathrm{l})$ của 7 kim loại nặng $\left(\mathrm{Pb} ; \mathrm{Hg} ; \mathrm{As} ; \mathrm{Cd} ; \mathrm{Cr}^{+3} ; \mathrm{Cu} ; \mathrm{Zn}\right)$ ở 5 tải trọng, trong khoảng tải trọng tối ưu từ 2.52- 5.87 $\left(\mathrm{KgCOD} / \mathrm{m}^{3}\right.$.ng.đ) theo thời gian $0,3,6,9$ (h) được mô tả trên bảng 1 cho thấy:

- Sự biến động hàm lượng $(\mathrm{mg} / \mathrm{l}) 3$ kim loại nặng $(\mathrm{Pb}, \mathrm{Hg}, \mathrm{As})$ trong nước thải công nghiệp CBTS, ở mỗi tải trọng thí nghiệm theo thời gian xử lý trong Aerotank luôn nhỏ hơn $10^{-4}(\mathrm{mg} / \mathrm{l})$. Đây là nồng độ rất nhỏ so với nồng độ $(\mathrm{mg} / \mathrm{l})$ cho phép $(\mathrm{Pb}, \mathrm{Hg}, \mathrm{As})$ có trong nước thải công nghiệp loại $\mathrm{B}$ theo TCVN 5945- 2005 và bảng giới hạn nồng độ $(\mathrm{mg} / \mathrm{l})$ cho phép các chất độc trong xử lý sinh học (As: 0.1; Hg: 0.01; Pb: 0.5) [1]; [5].

Như vậy, 3 kim loại nặng $(\mathrm{Pb}, \mathrm{Hg}$, As) có trong nước thải công nghiệp CBTS được coi như là không gây ô nhiễm cho thủy vực tiếp nhận nguồn thải.

- Hàm lượng (mg/l) 3 kim loại nặng $\left(\mathrm{Cr}^{+3} ; \mathrm{Cu} ; \mathrm{Zn}\right)$ là không lớn hơn nồng độ $(\mathrm{mg} / \mathrm{l})$ cho phép chúng có trong nước thải công nghiệp loại $\mathrm{B}$ theo TCVN 5945- 2005 và bảng giới hạn nồng độ $(\mathrm{mg} / \mathrm{l})$ cho phép chất độc trong xử lý sinh học $\left(\mathrm{Cd}: 0.01 ; \mathrm{Cr}^{+3}: 1.00 ; \mathrm{Cu}\right.$ : 1.00; Zn: 2.00) [1]; [5].

Như vậy, 3 kim loại nặng $\left(\mathrm{Cr}^{+3} ; \mathrm{Cu} ; \mathrm{Zn}\right)$ có trong nước thải công nghiệp CBTS có nồng độ nằm trong giới hạn nồng độ cho phép theo TCVN 5945- 2005 được xả thải ra môi trường. Riêng $\mathrm{Cd}$ có hàm lượng lớn hơn chút ít.

Tuy nhiên, chúng ta cũng cần nên nhắc lại rằng: $\mathrm{As}, \mathrm{Cd}, \mathrm{Pb}$ không có chức năng sinh học trong cơ thể người và chúng rất độc ngay cả ở lượng vết. Các kim loại $\mathrm{Pb} ; \mathrm{Cd}$; As; $\mathrm{Cu}$ luôn có sự gia tăng tích lũy trong các đối tượng nuôi (ốc Hương; Vẹm; Hải sâm; rong Sụn) từ nguồn thức ăn (tôm Tít, cua, ghẹ, cá tạp) và môi trường nuôi trong mô hình nuôi biển kết hợp [2].

Vì vậy, sự có mặt của 7 kim loại nặng $\left(\mathrm{Pb} ; \mathrm{Hg} ; \mathrm{As} ; \mathrm{Cd} ; \mathrm{Cr}^{+3} ; \mathrm{Cu} ; \mathrm{Zn}\right)$ trong nước thải công nghiệp CBTS có thể là nguy cơ tiềm năng, gây ô nhiễm cho thủy vực tiếp nhận nguồn thải và theo con đường tích lũy thực phẩm qua chuỗi thức ăn sẽ ảnh hưởng và gây nguy hiểm cho sức khỏe chúng ta. 
Bảng 1: Biến động hàm lượng 7 kim loại nặng theo thời gian xử lý ở khoảng tải trọng tối ưu

\begin{tabular}{|c|c|c|c|c|c|c|c|c|c|}
\hline $\begin{array}{l}\text { Thứ } \\
\text { tụ̣ }\end{array}$ & $\begin{array}{c}\text { Tải trọng } \\
\text { (KgCOD/ m }{ }^{3} \text {.ng.đ) }\end{array}$ & $\begin{array}{c}\text { Thời gian } \\
\text { xử lí (h) }\end{array}$ & $\begin{array}{c}\mathrm{Pb} \\
(\mathrm{mg} / \mathrm{l})\end{array}$ & $\begin{array}{c}\mathrm{Hg} \\
(\mathrm{mg} / \mathrm{l})\end{array}$ & $\begin{array}{c}\text { As } \\
(\mathrm{mg} / \mathrm{l})\end{array}$ & $\begin{array}{c}\mathrm{Cd} \\
(\mathrm{mg} / \mathrm{l})\end{array}$ & $\begin{array}{c}\mathrm{Cr}^{+3} \\
(\mathrm{mg} / \mathrm{l})\end{array}$ & $\begin{array}{c}\mathrm{Cu} \\
(\mathrm{mg} / \mathrm{l})\end{array}$ & $\begin{array}{c}\mathrm{Zn} \\
(\mathrm{mg} / \mathrm{l})\end{array}$ \\
\hline$\dot{1}$ & 3.852 & 0 & $<10^{-4}$ & $<10^{-4}$ & $<10^{-4}$ & 0.0134 & 0.6328 & 0.0682 & 0.1918 \\
\hline 2 & & 3 & $<10^{-4}$ & $<10^{-4}$ & $<10^{-4}$ & 0.0127 & 0.5629 & 0.066 & 0.1896 \\
\hline 3 & & 6 & $<10^{-4}$ & $<10^{-4}$ & $<10^{-4}$ & 0.0114 & 0.5566 & 0.0606 & 0.1847 \\
\hline 4 & & 9 & $<10^{-4}$ & $<10^{-4}$ & $<10^{-4}$ & 0.0107 & 0.5063 & 0.057 & 0.1668 \\
\hline 1 & 4.248 & 0 & $<10^{-4}$ & $<10^{-4}$ & $<10^{-4}$ & 0.0146 & 0.6975 & 0.0756 & 0.2113 \\
\hline 2 & & 3 & $<10^{-4}$ & $<10^{-4}$ & $<10^{-4}$ & 0.0137 & 0.6071 & 0.071 & 0.2032 \\
\hline 3 & & 6 & $<10^{-4}$ & $<10^{-4}$ & $<10^{-4}$ & 0.0122 & 0.598 & 0.0655 & 0.1864 \\
\hline 4 & & 9 & $<10^{-4}$ & $<10^{-4}$ & $<10^{-4}$ & 0.0113 & 0.545 & 0.0615 & 0.1721 \\
\hline 1 & 4.576 & 0 & $<10^{-4}$ & $<10^{-4}$ & $<10^{-4}$ & 0.0159 & 0.7515 & 0.0812 & 0.2271 \\
\hline 2 & & 3 & $<10^{-4}$ & $<10^{-4}$ & $<10^{-4}$ & 0.015 & 0.6491 & 0.0759 & 0.2162 \\
\hline 3 & & 6 & $<10^{-4}$ & $<10^{-4}$ & $<10^{-4}$ & 0.0132 & 0.6417 & 0.0698 & 0.1985 \\
\hline 4 & & 9 & $<10^{-4}$ & $<10^{-4}$ & $<10^{-4}$ & 0.0124 & 0.5806 & 0.0658 & 0.1832 \\
\hline 1 & 4.705 & 0 & $<10^{-4}$ & $<10^{-4}$ & $<10^{-4}$ & 0.0162 & 0.7728 & 0.0837 & 0.2336 \\
\hline 2 & & 3 & $<10^{-4}$ & $<10^{-4}$ & $<10^{-4}$ & 0.0154 & 0.6737 & 0.0783 & 0.1556 \\
\hline 3 & & 6 & $<10^{-4}$ & $<10^{-4}$ & $<10^{-4}$ & 0.0137 & 0.665 & 0.0722 & 0.2079 \\
\hline 4 & & 9 & $<10^{-4}$ & $<10^{-4}$ & $<10^{-4}$ & 0.0127 & 0.6013 & 0.0682 & 0.1921 \\
\hline 1 & 5.212 & 0 & $<10^{-4}$ & $<10^{-4}$ & $<10^{-4}$ & 0.0182 & 0.8556 & 0.0929 & 0.2588 \\
\hline 2 & & 3 & $<10^{-4}$ & $<10^{-4}$ & $<10^{-4}$ & 0.0177 & 0.7535 & 0.0881 & 0.2557 \\
\hline 3 & & 6 & $<10^{-4}$ & $<10^{-4}$ & $<10^{-4}$ & 0.0158 & 0.7457 & 0.0813 & 0.2354 \\
\hline 4 & & 9 & $<10^{-4}$ & $<10^{-4}$ & $<10^{-4}$ & 0.0148 & 0.6715 & 0.0769 & 0.2187 \\
\hline
\end{tabular}

\section{Hiệu suất xử lý $\mathrm{Cd} ; \mathrm{Cr}^{+3} ; \mathrm{Cu}$; $\mathrm{Zn}$ ở khoảng tải trọng tối ưu trên Aerotank}

Mặc dù các kim loại nặng nghiên cứu $\left(\mathrm{Pb} ; \mathrm{Hg} ; \mathrm{As} ; \mathrm{Cr}^{+3} ; \mathrm{Cu} ; \mathrm{Zn}\right)$ có nồng độ nằm trong vùng giới hạn nồng độ cho phép theo TCVN 5945- 2005 được xả thải ra môi trường (Riêng $\mathrm{Cd}$ có hàm lượng lớn hơn chút ít). Nhưng sự có mặt của các kim loại này trong nước thải công nghiệp CBTS vẫn có thể là nguy cơ tiềm năng gây ô nhiễm cho thủy vực tiếp nhận nguồn thải.

Vì vậy, nghiên cứu đã tiến hành xác định hiệu quả xử lí 4 kim loại nặng $\left(\mathrm{Cd} ; \mathrm{Cr}^{+3}\right.$; $\mathrm{Cu} ; \mathrm{Zn}$ ) có hàm lượng cao hơn trong nước thải công nghiệp CBTS bằng VSV có trong bùn hoạt tính trên Aerotank. Với 3 kim loại nặng $(\mathrm{Pb}, \mathrm{Hg}, \mathrm{As})$ do có nồng độ luôn nhỏ hơn $10^{-4}(\mathrm{mg} / \mathrm{l})$ nên nghiên cứu không đặt vấn đề xác định hiệu quả xử lí sinh học của chúng.

Kết quả nghiên cứu được mô tả và biểu thị trên bảng 2 và hình 2 về hiệu suất khử 4 kim loại nặng $\left(\mathrm{Cd} ; \mathrm{Cr}^{+3} ; \mathrm{Cu} ; \mathrm{Zn}\right)$ ở 5 tải trọng, trong khoảng tải trọng chất bẩn tối ưu từ 2.52- $5.87\left(\mathrm{KgCOD} / \mathrm{m}^{3}\right.$.ng.đ) theo thời gian xử lí $0,3,6,9$ (h) [3] cho thấy, hiệu suất xử lý trung bình 4 kim loại nặng $\left(\mathrm{Cd} ; \mathrm{Cr}^{+3} ; \mathrm{Cu} ; \mathrm{Zn}\right)$ trong Aerotank tại tải trọng tối ưu 4.576 $\left(\mathrm{KgCOD} / \mathrm{m}^{3}\right.$.ng.đ) thì hiệu suất xử lí $\mathrm{Cr}^{+3}$ là cao nhất $(\approx 17 \%)$. Tiếp đó là $\mathrm{Cd}(\approx 15.1 \%)$, 
$\mathrm{Cu}(\approx 13.2 \%)$ và cuối cùng là $\mathrm{Zn}(\approx 12.3 \%)$.

Bảng 2: Hiệu suất xử lý $(\eta \%) \mathrm{Cd} ; \mathrm{Cr}^{+3} ; \mathrm{Cu} ; \mathrm{Zn}$ trung bình trong khoảng tải trọng tối ưu

\begin{tabular}{|c|c|c|c|c|c|c|c|c|c|}
\hline $\begin{array}{c}\text { Thứ } \\
\text { tự }\end{array}$ & $\begin{array}{c}\text { Tải trong } \\
\text { KgCOD/ }^{\mathbf{3}} \text {.ng.d) }\end{array}$ & $\begin{array}{c}\text { Cd ra } \\
\text { tr.b }\end{array}$ & $\begin{array}{c}\boldsymbol{\eta} \% \\
\text { tr.b Cd }\end{array}$ & $\begin{array}{c}\mathbf{C r}^{+3} \mathbf{r a} \\
\text { tr.b }\end{array}$ & $\begin{array}{c}\boldsymbol{\eta} \% \text { tr.b } \\
\mathbf{C r}^{+3}\end{array}$ & $\begin{array}{c}\text { Cu ra } \\
\text { tr.b }\end{array}$ & $\begin{array}{c}\boldsymbol{\eta} \% \text { tr.b } \\
\text { Cu }\end{array}$ & $\begin{array}{c}\mathbf{Z n} \text { ra } \\
\text { tr.bình }\end{array}$ & $\begin{array}{c}\boldsymbol{\eta} \% \text { tr.b } \\
\text { Zn }\end{array}$ \\
\hline 1 & 3.852 & 0.0116 & 13.43 & 0.5419 & 14.36 & 0.0612 & 10.26 & 0.1777 & 7.35 \\
\hline 2 & 4.248 & 0.0124 & 15.07 & 0.6238 & 16.36 & 0.0660 & 12.69 & 0.1873 & 11.38 \\
\hline 3 & 4.576 & 0.0135 & 15.09 & 0.6467 & 16.99 & 0.0705 & 13.18 & 0.1993 & 12.24 \\
\hline 4 & 4.705 & 0.0139 & 14.20 & 0.5834 & 16.32 & 0.0729 & 12.90 & 0.2086 & 10.70 \\
\hline 5 & 5.212 & 0.0161 & 11.54 & 0.7236 & 15.43 & 0.0821 & 11.63 & 0.2366 & 8.58 \\
\hline
\end{tabular}

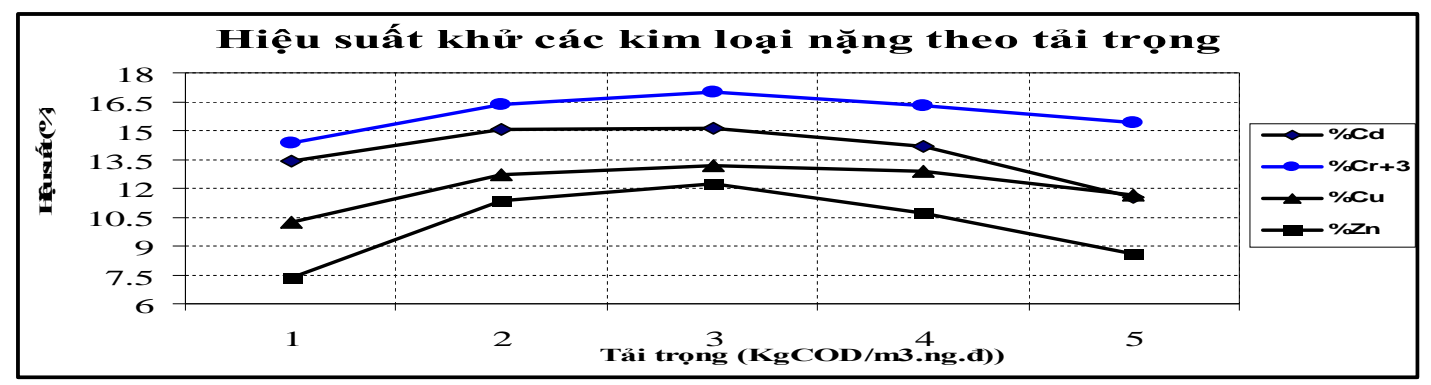

Hình 2: Biểu đồ so sánh hiệu suất xử lý 4 kim loại nặng $\left(\mathrm{Cd} ; \mathrm{Cr}^{+3} ; \mathrm{Cu} ; \mathrm{Zn}\right)$ theo tải trọng

Nếu so với hiệu suất xử lí sinh hóa COD trên Aerotank, ở cùng thời gian lưu thủy lực tối ưu $18 \mathrm{~h}$, tại tải trọng chất bẩn tối ưu $4.51\left(\mathrm{KgCOD} / \mathrm{m}^{3}\right.$.ng.đ) là $98.96 \%$ [3] thì hiệu suất xử lí các kim loại nặng trên là quá nhỏ. Vì vậy, với các kim loại nặng này cần phải nghiên cứu các phương pháp xử lý khác như phương pháp hoá học, phương pháp hoá lý, phương pháp kị khí, ao hồ sinh học tự nhiên, ... để cho hiệu suất xử lý được cao hơn.

\section{KẾT LUẬN VÀ KIẾN NGH!}

Từ các kết quả nghiên cứu trên, cho phép rút ra một số kết luận về hàm lượng và hiệu quả xử lí sinh học 7 kim loại nặng $\left(\mathrm{Pb} ; \mathrm{Hg} ; \mathrm{As} ; \mathrm{Cd} ; \mathrm{Cr}^{+3} ; \mathrm{Cu} ; \mathrm{Zn}\right)$ có trong nước thải công nghiệp CBTS trên Aerotank như sau:

1. Nồng độ của $\mathrm{Pb}, \mathrm{Hg}, \mathrm{As}$ là rất nhỏ so với nồng độ cho phép có trong nước thải công nghiệp loại $\mathrm{B}$ theo TCVN 5945- 2005 và bảng giới hạn nồng độ cho phép các chất độc trong xử lý sinh học.

2. Nồng độ của $\mathrm{Cd}$ lớn hơn chút ít so với nồng độ cho phép có trong nước thải công nghiệp loại $\mathrm{B}$ theo TCVN 5945- 2005 và bảng giới hạn nồng độ cho phép các chất độc trong xử lý sinh học. 
3. Nồng độ của $\mathrm{Cr}^{+3} ; \mathrm{Cu} ; \mathrm{Zn}$ nằm trong giới hạn nồng độ cho phép có trong nước thải công nghiệp loại $\mathrm{B}$ theo TCVN 5945- 2005 và bảng giới hạn nồng độ cho phép các chất độc trong xử lý sinh học.

4. Hiệu suất xử lý sinh học 4 kim loại nặng $\left(\mathrm{Cd} ; \mathrm{Cr}^{+3} ; \mathrm{Cu} ; \mathrm{Zn}\right)$ trong Aerotank là rất thấp và giảm theo thứ tự: $\mathrm{Cr}^{+3}>\mathrm{Cd}>\mathrm{Cu}>\mathrm{Zn}$.

5. Cần phải nghiên cứu các phương pháp xử lý khác để hiệu suất xử lý các kim loại nặng được cao hơn.

\section{TÀI LIỆU THAM KHẢO}

1. Các tiêu chuẩn Nhà nước Việt Nam về môi trường, 2005. Tập 1: Chất lương nước TCVN 5945- 2005. Nước thải công nghiẹp- Tiêu chuẩn thải. Industrial wastewater-Discharge standards.

2. Đặng Thúy Bình; Nguyễn Thanh Sơn; Nguyễn Thị Thu Nga, 2006. Nghiên cứu sụ tích lũy kim loại nặng trong ốc Hương và một số đối tương thủy sản (Vẹm, Hải sâm, rong Sụn) tại đảo Điệp sơn, vịnh Vân phong, Khánh hòa. Tạp chí khoa học công nghệ Thủy sản số 03-04/2006, trang 44- 52.

3. Nguyễn Phước Hòa, 2007. Luận án Tiến sĩ kĩ thuật, chuyên ngành công nghệ CBTS. Mã số: 62.54.10.05: "Nghiên cưu biến động các thành phần hưu co" trong nước thải công nghiệp chế biến Thủy sản và mô hình xử li’”. Bộ giáo dục và đào tạo, Đại học Nha trang.

4. Nguyễn Tác An, 1996. Phương pháp quản lí chất lượng nước phục vu nuôi trồng Thủy hải sản. Viện hải dương học Nha trang- Đại học Thủy sản Nha trang.

5. Trần Hiếu Nhuệ, 1999. Thoát nước và xử lí nước thải công nghiệp. NXB KHKT, Hà Nội.

\section{RESULT OF RESEARCH ON THE CONTENT AND THE HEAVY METAL TREATMENT POSSIBILITY IN WASTEWATER FROM SEAFOOD PROCESSING INDUSTRIES ON THE AEROTANK}

\section{NGUYEN PHUOC HOA}

Summary: The report presents the results of studies on the variation of content and effective of biological treatment of seven heavy metals ( $\left.\mathrm{Pb} ; \mathrm{Hg} ; \mathrm{As} ; \mathrm{Cd} ; \mathrm{Cr}^{+3} ; \mathrm{Cu} ; \mathrm{Zn}\right)$ in wastewater from seafood processing industries on the Aerotank at optimum load around 2.52$5.87\left(\mathrm{KgCOD} / \mathrm{m}^{3} .24\right.$ hours $)$ and optimum hydraulic retention time about 18 hours.

Ngày nhận bài: 07 - 05 - 2011

Người nhận xét: PGS. TSKH. Nguyễn Tác An 